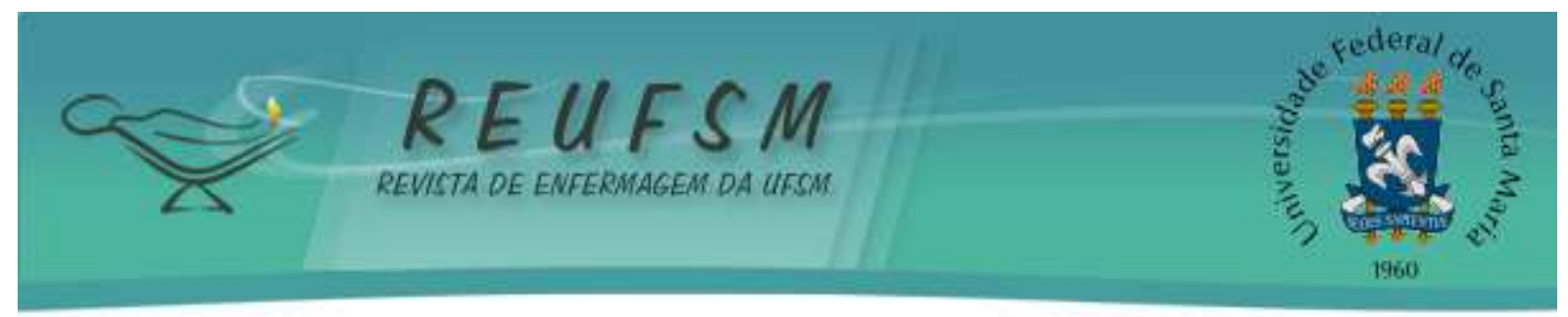

\title{
ZIKA VÍRUS: SENTIMENTOS E PRÁTICAS DE CUIDADOS DE GESTANTES
}

ZIKA VIRUS: FEELINGS AND PRACTICES OF CAREGIVERS

ZIKA VIRUS: SENTIMIENTOS Y PRÁCTICAS EN LOS CUIDADOS DE GESTANTES

Doi: $10.5902 / 2179769230497$

Francisca Weslla Oliveira da Silva ${ }^{1}$

Kariane Gomes Cezario Roscoche ${ }^{2}$

Raimunda Juliana Oliveira Farias ${ }^{3}$

Luiza Aurela Filha Abreu ${ }^{4}$

Albertina Antonielly Sydney de Sousa ${ }^{5}$

Anne Fayma Lopes Chaves ${ }^{6}$

RESUMO: Objetivo: descrever os sentimentos e práticas de cuidado de gestantes diante do risco de contrair o Zika vírus. Método: estudo qualitativo, realizado nos meses de outubro e novembro de 2016 em uma Instituição de Ensino Superior privada, com 10 gestantes. Para coleta de dados utilizou-se formulário com perguntas estruturadas e entrevista aberta, com categorização das falas conforme a técnica de Análise Temática. Resultados: da análise dos dados, emergiram as categorias: Sentimentos das gestantes diante do Zika vírus e Zika vírus e as estratégias de enfrentamento pelas gestantes. Conclusões: as gestantes apresentaram sentimentos de preocupação, medo e insegurança diante do Zika vírus. Contudo, os métodos preventivos juntamente com os exames realizados no pré-natal proporcionaram impacto positivo, gerando segurança entre as mulheres e ajuste de sua rotina em tempos de surto do Zika vírus.

Descritores: Emoções; Zika virus; Gestantes; Cuidados de enfermagem

ABSTRACT: Objective: to describe the feelings and care practices of pregnant women facing the risk of contracting the Zika virus. Method: qualitative study, carried out in October and November of 2016 in a Private Higher Education Institution, with 10 pregnant women. For data collection, a structured questionnaire and an open interview was used, with categorization of the lines according to the Thematic Analysis technique. Results: from the data analysis, the following categories emerged: Feelings of pregnant women in front of Zika virus and Zika virus and coping strategies by pregnant women. Conclusions: pregnant women presented feelings of worry, fear and insecurity about the Zika virus. However, the preventive methods along with prenatal examinations provided positive impact, generating safety among women and adjusting their routine in times of outbreak of the Zika virus.

Descriptors: Emotions; Zika virus; Pregnant women; Nursing care

\footnotetext{
${ }^{1}$ Enfermeira. Bacharel em Enfermagem. Centro Universitário Estácio do Ceará. Fortaleza, CE, Brasil. E-mail: weslla_enfa@hotmail.com

${ }^{2}$ Enfermeira. Doutora em Enfermagem. Universidade Estadual de Ponta Grossa. Curitiba, PR, Brasil. E-mail: kariane_gomes@yahoo.com.br

${ }^{3}$ Enfermeira. Bacharel em Enfermagem. Centro Universitário Estácio do Ceará. Fortaleza, CE, Brasil. E-mail: lan_foxhouse@hotmail.com

${ }^{4}$ Enfermeira. Bacharel em Enfermagem. Centro Universitário Estácio do Ceará. Fortaleza, CE, Brasil. E-mail: luizaabreusud@yahoo.com.br

${ }^{5}$ Enfermeira. Doutora em Enfermagem. Universidade da Integração Internacional da Lusofonia Afro-Brasileira. Fortaleza, CE, Brasil. E-mail: albertina_sousa@ hotmail.com

${ }^{6}$ Enfermeira. Doutora em Enfermagem. Universidade da Integração Internacional da Lusofonia Afro-Brasileira. Fortaleza, CE, Brasil. E-mail: annefayma@yahoo.com.br
} 


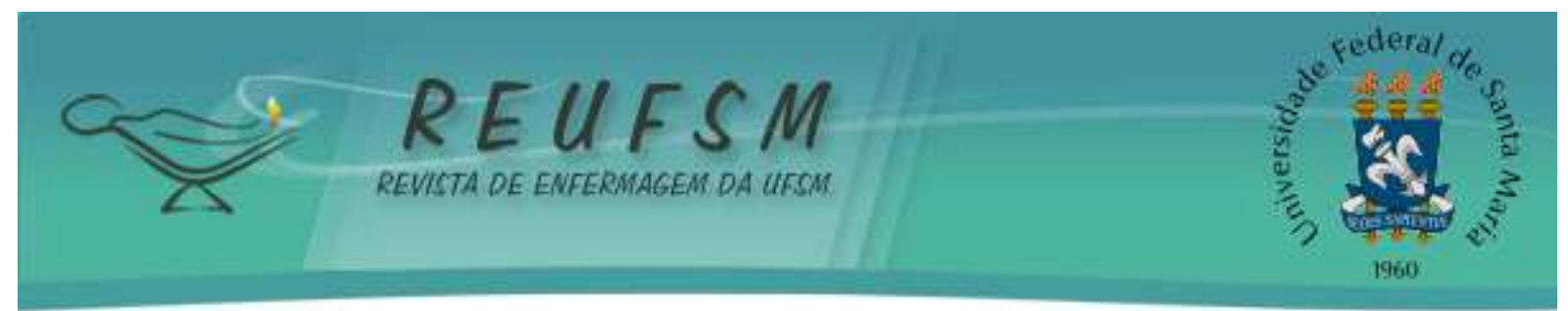

ABSTRACT: Aim: to describe the feelings and care practices of pregnant women facing the risk of contracting the Zika virus. Method: qualitative study, carried out in October and November 2016 in a Private Higher Education Institution, with 10 pregnant women. For data collection, a structured questionnaire and an open interview were used, with categorization of the speeches according to the Thematic Analysis technique. Results: from the data analysis, the following categories emerged: Feelings of pregnant women in front of Zika virus and Zika virus and pregnant women's coping strategies. Conclusions: pregnant women presented feelings of concern, fear and insecurity about the Zika virus. However, the preventive methods along with prenatal examinations provided positive impact, generating safety among women and adjusting their routine in times of outbreak of the Zika virus.

Descriptores: Emociones; Zika virus; Las mujeres embarazadas; Cuidados de enfermería

\section{INTRODUÇÃO}

$\mathrm{O}$ aumento de casos de infecção pelo Zika vírus relaciona-se com o crescimento inesperado no nascimento de crianças com microcefalia, acontecimento inédito observado na região nordeste do Brasil, no período de outubro de 2015. ${ }^{1}$ A totalidade dos desfechos das ocorrências registradas de Zika em todo o país, acompanhados desde 2016 até 2017, gera o valor total de 231.793 casos prováveis. Destes, 2.105 foram registrados em relação às gestantes, sendo 728 confirmados por critério clínico-epidemiológico ou laboratorial. ${ }^{2}$

A associação entre a infecção pelo Zika vírus e a ocorrência de microcefalia em recémnascidos foi confirmada em 2015 mediante amostras de sangue e tecidos de um recémnascido no Ceará que apresentava microcefalia e outras malformações congênitas. ${ }^{3}$ A microcefalia, até então considerada rara, subnotificada e associada especialmente a problemas genéticos, ganhou evidência com associação à infecção pelo Zika vírus, tornando-se uma doença teratogênica gerando risco à saúde perinatal. ${ }^{4}$

O vetor responsável pela transmissão do Zika vírus é o mosquito Aedes aegypti e, atualmente, não há nenhum tratamento antiviral ou vacina disponível, sendo a melhor forma de prevenção a proteção contra a picada do inseto e a redução da densidade vetorial. Os cuidados preconizados consistem em evitar horários e lugares com presença do vetor; utilizar continuamente roupas que protejam partes expostas do corpo, especialmente braços e pernas; eliminar possíveis criadouros do A. aegypti, realizar a limpeza dos terrenos, proceder ao descarte apropriado do lixo de materiais e reaproveitar adequadamente a água; permanecer em locais com barreiras para entrada de inseto, e fazer uso de telas de proteção e mosquiteiros. ${ }^{5} \mathrm{O}$ 


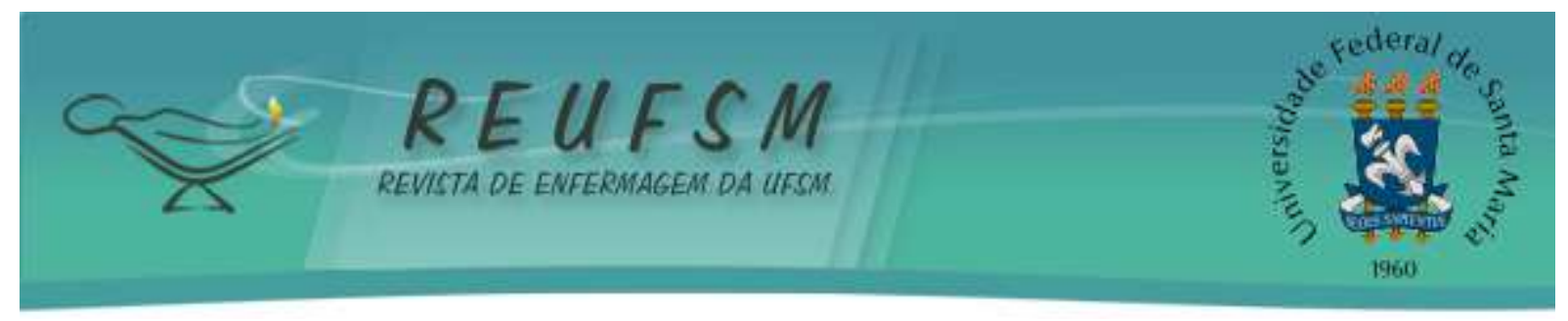

uso de repelentes tem sido recomendado desde que o mesmo seja a base de N, N-dimetilmeta-toluamida (DEET) e registrado pela Agência Nacional de Vigilância Sanitária. ${ }^{6}$

Frente a uma infecção na qual não há proteção específica e com potencial teratogênico, desponta nas mães, durante todo o curso da gestação, o medo de que o filho seja acometido pela microcefalia. Nesse contexto, as grávidas também se deparam com situações que as fazem se questionar sobre prosseguir com a gravidez e sua capacidade de enfrentar as dificuldades que, por ventura, se apresentem, sendo necessário que a equipe de saúde esteja capacitada para acolher e orientar essa gestante. ${ }^{7}$

Acresce-se a isso o fato de que a gravidez é um período de transição relevante na vida da mulher. Nessa etapa, acontecem várias modificações fisiológicas e no estado emocional, o que enseja atenção especial para manter o bem-estar e prevenir dificuldades futuras. Os eventos estressores são fatores de alto risco para maior vulnerabilidade emocional, a qual está associada a alterações de humor, ansiedade, baixa concentração, irritabilidade, mudança no apetite, insônia, hipersonia e perda de energia. ${ }^{8}$

Reflete-se que tais consequências podem afetar negativamente as gestantes, as quais se preparam para gerar uma criança sadia e se deparam com o medo de conceber uma criança com deficiências associadas à microcefalia. Desta forma, o enfermeiro deve ter adequado conhecimento teórico a respeito da infecção pelo Zika vírus tanto para informar as mulheres, quanto para atuar na perspectiva de prevenção da doença por meio de ações estratégicas.

No âmbito do relacionamento terapêutico com a gestante, destaca-se que a escuta qualificada constitui uma importante ferramenta do cuidado, pois possibilita compreender o sofrimento psíquico a partir da pessoa e valorizar suas experiências, necessidades e diferentes aspectos que compõem seu cotidiano. ${ }^{9}$ No contexto da Zika, esta estratégia é fundamental para proporcionar segurança emocional à mulher durante sua gestação.

Nesse contexto, surgiu o seguinte questionamento: quais os sentimentos e práticas de cuidado de gestantes diante do risco de contrair o Zika vírus?

A relevância da pesquisa reside no fato de que, a partir do conhecimento das vivências e sentimentos das gestantes diante do risco de contrair o Zika vírus, os profissionais de saúde, especialmente os enfermeiros, terão subsídios para traçar estratégias no intuito de proporcionar uma atenção pré-natal mais qualificada, que envolva apoio informacional e 


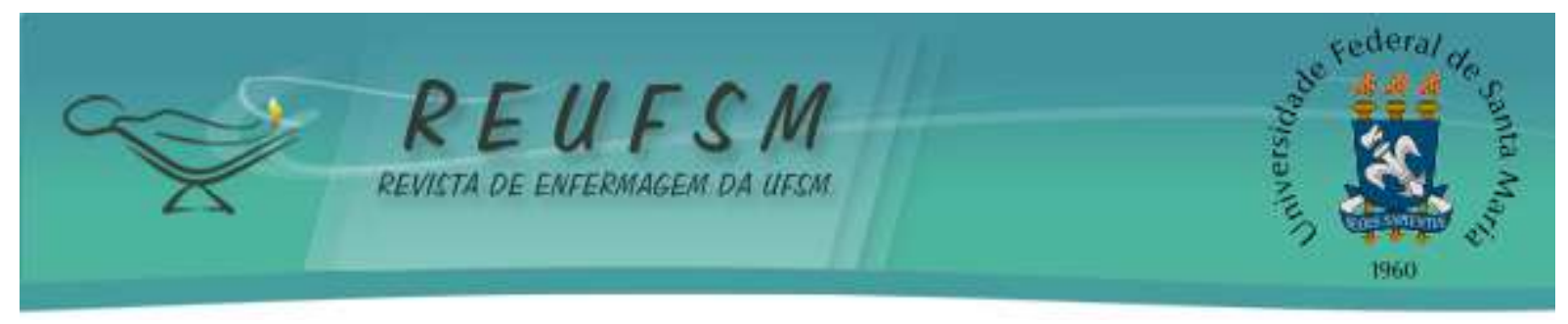

emocional. Desta forma, o objetivo da pesquisa foi descrever os sentimentos e práticas de cuidado de gestantes diante do risco de contrair o Zika vírus.

\section{MÉTODO}

Trata-se de um estudo qualitativo, realizado com gestantes de uma Instituição de Ensino Superior (IES) privada em Fortaleza, Ceará, Brasil. A pesquisa qualitativa descreve a essência do pensar pelo ser humano em suas diferentes manifestações, não considerando a quantificação dos fenômenos, mas a experiência dos indivíduos. ${ }^{10}$

As gestantes estudavam ou trabalhavam na IES. A seleção das participantes foi realizada na modalidade Snowball (Bola de Neve), ou seja, foram contatadas a partir da indicação de seus pares, tais como colegas de sala de aula ou de trabalho que tinham conhecimento de suas respectivas gestações. Após a indicação, as mesmas foram convidadas a participar do estudo via contato telefônico ou abordagem direta e, caso aceitassem, era realizado o agendamento da entrevista na própria IES, tendo como cenário as salas de aula desocupadas nos intervalos.

Participaram dez gestantes, sendo incluídas as com idade igual ou superior a dezoito anos; vinculadas à IES; independente do período gestacional. Salienta-se que a escolha de gestantes a partir dos 18 anos foi justificada por estas não necessitarem de Termo de Assentimento, conferindo maior rapidez ao procedimento de coleta dos dados.

O número de participantes foi delimitado por saturação teórica, técnica comum nas pesquisas qualitativas, ${ }^{11}$ na qual a coleta de dados é interrompida quando as informações se tornam repetitivas.

A coleta de dados foi realizada entre outubro e novembro de 2016, em dia e horário determinado pelas participantes, e as mesmas foram orientadas previamente quanto aos procedimentos. Como instrumento, utilizou-se um questionário previamente elaborado com informações sobre dados socioeconômicos, antecedentes obstétricos e uma entrevista aberta com a questão norteadora: "Quais os seus sentimentos e vivências diante do surto de Zika vírus?". Ressalta-se que as entrevistas ocorreram em local reservado e duraram em média quinze minutos; as falas foram gravadas por meio do recurso de gravador de áudio do aparelho celular do pesquisador, mediante autorização das gestantes.

Os dados coletados foram organizados e transcritos na íntegra no software de texto Microsoft Word $^{\circledR}$. A análise dos mesmos procedeu segundo a técnica de Análise Temática, a 


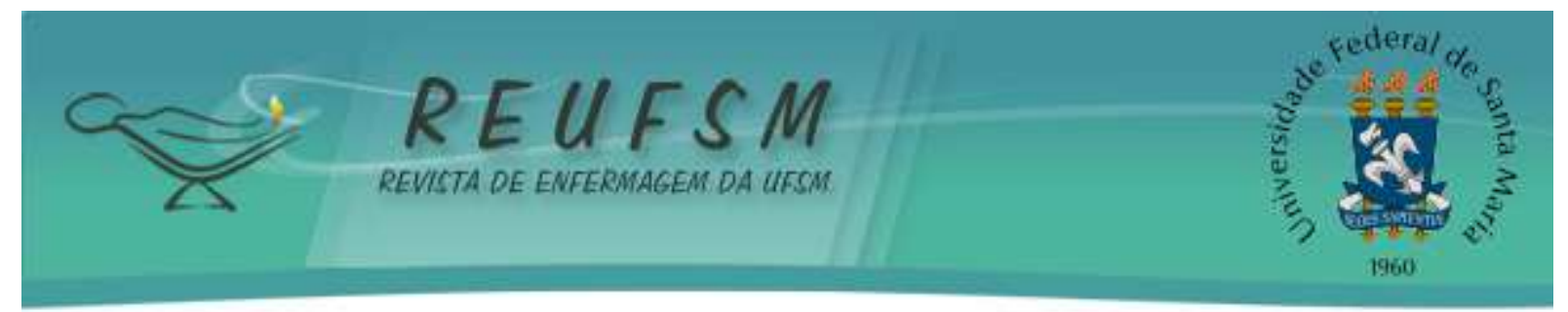

qual é composta das seguintes etapas: (1) pré-análise, que consiste na organização do material a ser analisado por meio de leitura flutuante, constituição do corpus da análise e formulação de hipóteses e objetivos; (2) exploração do material por meio da identificação/definição de categorias empíricas emergentes; e (3) tratamento e interpretação dos resultados, que consiste no destaque das informações para análise, culminando nas interpretações inferenciais. ${ }^{12}$

Da análise dos dados emergiram as categorias: "Sentimentos das gestantes diante do Zika vírus" e "Zika vírus e as estratégias de enfrentamento pelas gestantes", as quais foram discutidas com base na literatura pertinente.

As gestantes foram devidamente informadas sobre os objetivos da pesquisa e atestaram sua concordância em participar, mediante a assinatura do termo de consentimento livre e esclarecido fornecido em duas vias: uma para o participante e a outra para o pesquisador. Para preservar o anonimato, as participantes foram identificadas com pseudônimos de flores. $\mathrm{O}$ estudo foi submetido à apreciação de Comitê de Ética em Pesquisa e obteve parecer favorável em 25 de outubro de 2016, sob o protocolo $\mathrm{n}^{\circ}$ 1.791.951, respeitando os critérios éticos do Conselho Nacional de Saúde, através da Resolução No 466/12 do Ministério da Saúde. ${ }^{13}$

\section{RESULTADOS E DISCUSSÃO}

A idade das participantes variou entre 21 e 34 anos, sendo a maioria (sete mulheres) casada ou vivendo em união estável. Todas apresentavam nível superior completo ou estavam cursando, com renda mensal variando entre um e vinte e dois salários mínimos.

Em relação à ocupação, três eram docentes da Instituição, três eram técnicas de enfermagem, três eram estudantes e uma era auxiliar administrativa. Quanto aos antecedentes obstétricos, sete delas era multíparas, três eram primigestas e não apresentavam histórico de complicações durante a gravidez.

\section{Sentimentos das gestantes diante do Zika vírus}

Os sentimentos mais relatados pelas mulheres foram preocupação, medo e insegurança. A presença constante da temática na mídia, a curiosidade existente na rede social de apoio e o medo de que a alteração afetasse seu próprio filho, levaram as mulheres a vivenciar distintos sentimentos diante de tal problemática. 


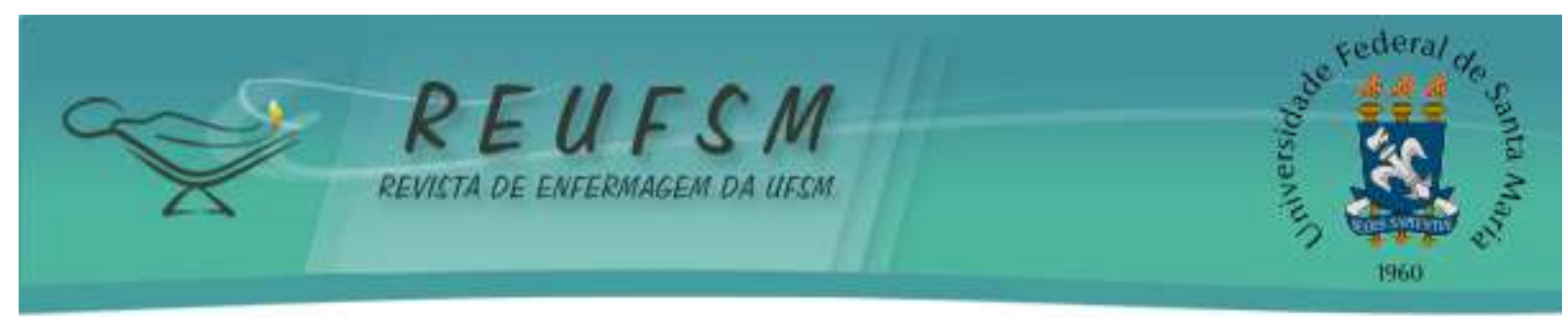

O meu sentimento é de medo, de ter um filho com uma deficiência que vai acompanhá-lo pelo resto da vida [...]. (Acácia)

Em relação ao sentimento o que eu sinto é insegurança, porque no meu primeiro ultrassom não dava para ver muita coisa, e eu ficava naquela preocupação [...]. (Flor de Liz)

A contaminação pelo Zika vírus se tornou fonte de preocupação mundial para as organizações de saúde, sendo divulgada em jornais, revistas e na mídia virtual de forma recorrente o que, por vezes, provocou nas gestantes o sentimento de medo, apreensão e insegurança. ${ }^{7}$ Percebe-se que a gestação, geralmente se constitui em um momento de alegria e satisfação na vida da mulher, no entanto, para estas gestantes em particular, tornou-se um momento de insegurança, aflição e desorganização emocional. Esse tipo de manifestação pode repercutir negativamente sobre a saúde mental destas mulheres.

O suporte emocional é um importante fator de proteção e promoção de saúde mental aos pais e demais familiares. Desta forma, capacitação e treinamento devem ser oferecidos e facilitados para que os profissionais de saúde possam atuar de forma eficaz nesta perspectiva de cuidado. É preciso considerar a necessidade de apoio psicológico que auxilie no desenvolvimento de estratégias de enfrentamento diante dos prejuízos do desenvolvimento intelectual que poderão acometer as crianças afetadas pelo Zika. ${ }^{14}$

Percebe-se que os sentimentos negativos referidos pelas gestantes tem uma forte relação com a falta de informação sobre o Zika vírus. Apesar da ampla divulgação pela mídia, muitas informações ainda não estavam totalmente claras e confirmadas, o que reforçava a dúvida e angústia acerca da doença do bebê. Além disso, pela forma como muitas notícias foram veiculadas, gerou-se intensa preocupação e até pânico entre as gestantes.

No começo eu fiquei muito assustada e preocupada, porque é tudo muito novo [Zika vírus]. Eu não sabia exatamente do que se tratava, daí eu comecei a buscar mais informações sobre o assunto, pois não se tratava só de mim, e sim da vida do meu filho. (Dália)

Os sentimentos são de insegurança, pavor, é por conta de informações [inéditas], não se sabe realmente as consequências [para o filho], nem mesmo os profissionais sabem tudo. (Íris)

Cada dia eles descobrem uma coisa diferente, um dia é susceptível a três meses de gestação, depois eles dizem que a criança pode adquirir Zika e desenvolver quando nascer. (Camélia)

A internet e outros instrumentos de comunicação como a televisão, são ferramentas facilitadoras para o acesso à informação, no entanto devem ser utilizadas com cautela no 


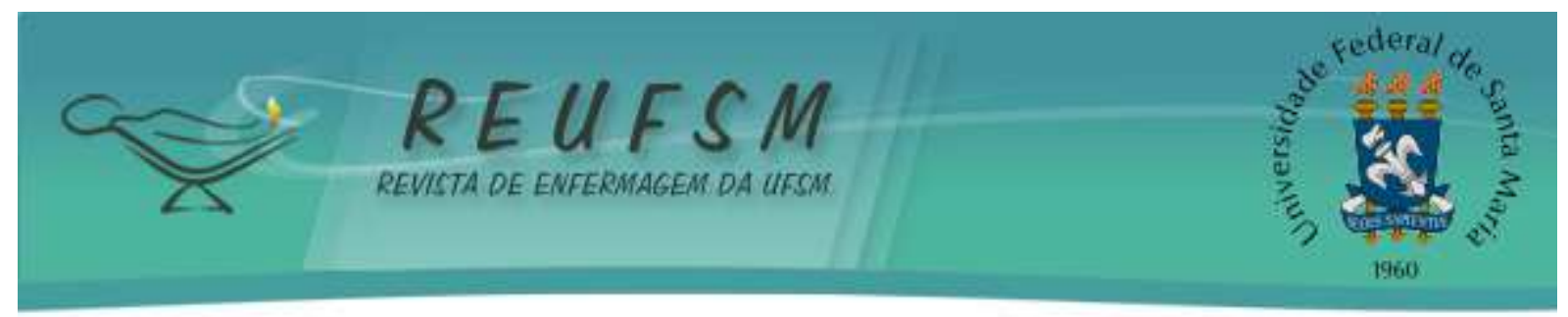

tocante à veracidade de algumas informações, tendo em vista sua possível influência sobre as práticas de saúde. Desta forma, é recomendado que os profissionais da saúde assumam o papel de principais disseminadores de conhecimento sobre Zika vírus. No contexto da Enfermagem, ressalta-se que a equipe deve ser capacitada para o acolhimento e o reconhecimento dos fatores que estão correlatos com a sintomatologia da infecção para desenvolverem estratégias de educação em saúde que visem a promoção do autocuidado.

Embora se reconheça a importância dos conteúdos sobre o Zika vírus serem fornecidos pelo profissional de saúde neste estudo, quando interrogadas sobre este aspecto, a maioria das mulheres relatou lacuna quanto às orientações prestadas pelos profissionais de saúde e mostraram-se inseguras diante de tantas notícias incertas.

Esses achados podem ser explicados pelo fato do Zika ser uma doença nova no Brasil, onde o conhecimento ainda não é concreto e sólido, o que leva a muitas dúvidas. $\mathrm{O}$ acesso à informação de confiança associado aos esclarecimentos dos profissionais sobre os mitos e verdades da doença às gestantes e familiares, pode ser utilizado como prática de cuidados à saúde, eliminando notícias equivocadas que circulam, por exemplo, nas redes sociais.

Assim o acolhimento à gestante diante de suas angústias, medos e dúvidas, por meio de uma escuta atenciosa e qualificada, pode culminar no encontro de esperança e força por meio do apoio recebido pelos profissionais de saúde. ${ }^{15-16}$ Desse modo, cabe à equipe de saúde viabilizar o contato com as gestantes que buscam a compressão dos múltiplos significados da gestação, oportunizando escutar suas reflexões, medos e anseios, para que se estabeleça um elo de confiança com o profissional. ${ }^{17}$

Outro achado importante neste estudo, diz respeito ao resultado sem alterações dos exames de ultrassonografia como fator de segurança para a mãe quanto à saúde do bebê.

Eu me sinto um pouco angustiada, não vejo cura [Zika], só tratamento. $O$ que me deixa segura mesmo é quando eu faço a morfológica [ultrassonografia]. (Hortênsia)

Apesar de ser um meio real de se atestar a saúde do bebê, o exame de ultrassonografia revela uma tranquilidade apenas momentânea para a gestante, isto é, a percepção de proteção dura um curto espaço de tempo. Isso acontece porque a infecção pelo Zika vírus pode ocorrer em qualquer etapa da gestação, gerando ansiedade no momento de realização do exame, e no aguardo pelos posteriores. Geralmente, no que concerne aos sentimentos da mulher à descoberta da gravidez, os mesmos são inicialmente negativos; porém, a partir do resultado do exame de 


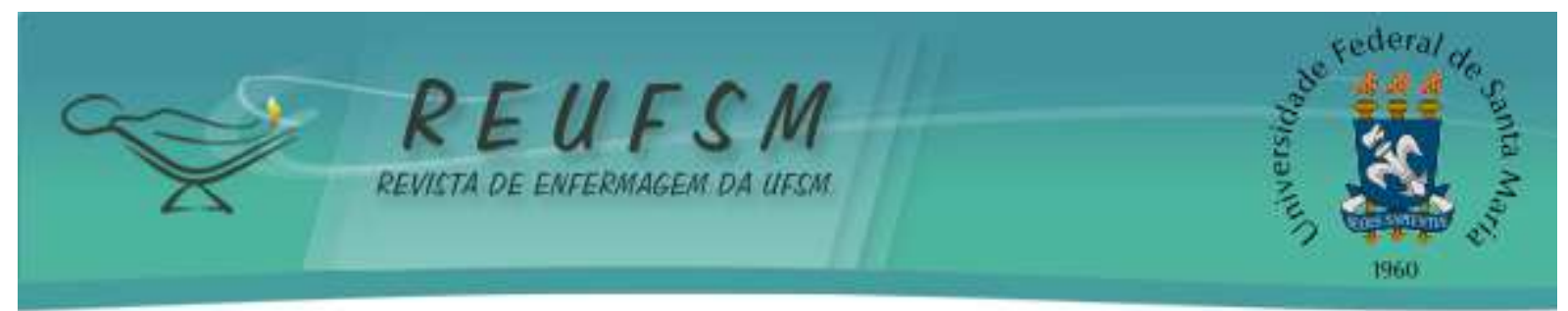

ultrassonografia, passam a ser substituídos por alegria, por possibilitar uma maior interação com o bebê. ${ }^{18}$ Neste estudo, no entanto, percebeu-se que o sentimento de insegurança e medo aumentava à medida que a gestação progredia e, com ela, a necessidade de realizar o exame de ultrassom.

Diante da associação do Zika vírus com a microcefalia, as políticas de saúde visam garantir o cuidado adequado às gestantes e bebês na respectiva atenção à saúde, visto que diversos danos e agravos podem surgir. Ampliam, assim, os diversos métodos de prevenção e promoção da saúde, com visitas domiciliares para orientação à população e o acompanhamento das gestantes, puérperas e recém-nascidos suspeitos de microcefalia, como também a disseminação correta dos agravos à saúde da gestante, visando atender de forma holística e integral. ${ }^{5}$

\section{Zika vírus e as estratégias de enfrentamento pelas gestantes}

A principal estratégia adotada pelas gestantes para enfrentar o Zika vírus esteve relacionada à modificação da rotina. As mulheres relataram incorporar diversos métodos de proteção, dentre os quais se destacaram o uso de produtos e de vestimentas que cobrissem todo o corpo. Segundo os relatos, estas atitudes permitiam se sentir mais seguras e protegidas do mosquito.

[...] Eu me cerquei de todos os métodos preventivos, como uso de repelentes, roupas em excesso que pudessem cobrir toda a parte do corpo. (Acácia)

[...] Quando eu soube que estava grávida a primeira providência foi comprar repelente e pijama de manga comprida e de calça comprida. (Gardênia)

[...] Eu me previno muito, evito ficar em ambientes que tenham muita plantação, que tenha água, uso repelente de duas em duas horas, mesmo que esteja indicado usar de seis em seis horas. (Hortênsia)

Considerando a alta infestação por Aedes aegypti, recomenda-se que as medidas de prevenção e controle sejam orientadas para reduzir a densidade do vetor, protegendo-se das picadas de insetos durante a gestação, evitando horários e lugares com presença de mosquitos. Sempre que possível, utilizar roupas que protejam partes expostas do corpo, consultar o médico sobre o uso de repelentes e fazer uso de barreiras para entrada de insetos como telas de proteção, mosquiteiros, ar-condicionado ou outras disponíveis. ${ }^{19}$ Percebe-se, pois, que as gestantes adotaram novos hábitos alinhados às recomendações do Ministério da Saúde.

O enfermeiro, durante as consultas de rotina no pré-natal, precisa orientar as gestantes sobre o uso correto dos repelentes e inseticidas sanando todas as dúvidas, para que essas 


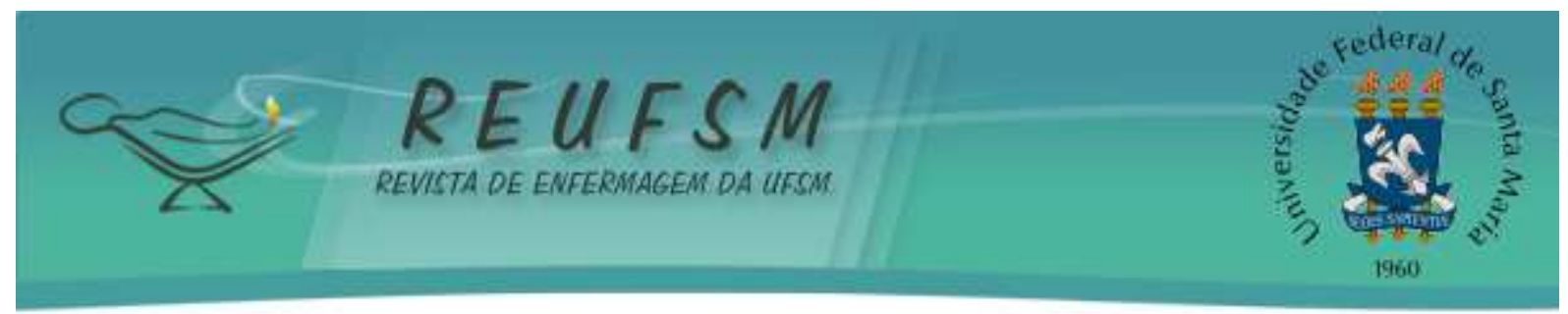

mulheres se sintam mais seguras quanto aos métodos preventivos. Normalmente, os repelentes trazem a recomendação de uso para gestantes em suas embalagens, bem como o intervalo de horários preconizado. ${ }^{20}$

Além das mudanças na rotina mencionadas, outra estratégia identificada pelas gestantes foi em relação ao apoio social percebido. Houve relato da notória colaboração dos amigos ao divulgarem informações sobre a infecção pelo vírus nos espaços de convivência.

Frequentamos uma igreja, e lá é bem grande, o espaço é como se fosse um sítio, e eu fiquei sim bastante preocupada, mas pedimos a cooperação de todos [amigos], fizemos a conscientização [Zika vírus] sobre os alertas e os cuidados. (Anis)

Algumas modificações na rotina das gestantes podem levar a problemas emocionais nos relacionamentos sociais e conjugais, caso elas não recebam o devido apoio. O cuidado de mulheres grávidas demanda envolvimento de pessoas de seus círculos de confiança, a fim de lhes dar o devido suporte. Estas pessoas podem ser o companheiro, amigos, familiares ou grupos comunitários. Se a mulher tem um companheiro, geralmente é útil inclui-lo na discussão, para incentivar o apoio mútuo, tendo em vista que as mudanças cotidianas até podem ser harmoniosas entre alguns casais, porém podem levar ao esgotamento emocional em outros. ${ }^{16,21}$

Observou-se em estudo que a formação de grupos de apoio a gestantes que passam por preocupações ao longo do período gestacional culmina em apoio por oferecer acolhimento, interação sincera e expressão de suas emoções sem julgamento, fazendo desse encontro uma oportunidade para revelar seus sentimentos. ${ }^{18}$ Sendo assim, foi possível perceber que um espaço de apoio apresenta-se como uma prática de cuidados que facilita a troca de experiências entre as gestantes e o companheiro que também necessita de atenção.

No contexto do exame de ultrassom, mesmo após a confirmação da normalidade do perímetro cefálico do feto, as mães ainda relataram sentimento de insegurança, porém mencionaram a fé como fonte de apoio. Segundo elas, a fé era um meio de proteção para o filho que estavam esperando e força para superar as dificuldades, caso houvesse a possibilidade da existência de malformações fetais, principalmente a microcefalia.

Por mais que eu tenha entregado a vida do meu filho a Deus, eu sempre senti aquela insegurança de dizer assim, ai meu Deus proteja ele [filho], que esteja tudo bem. (Flor de Lis) 


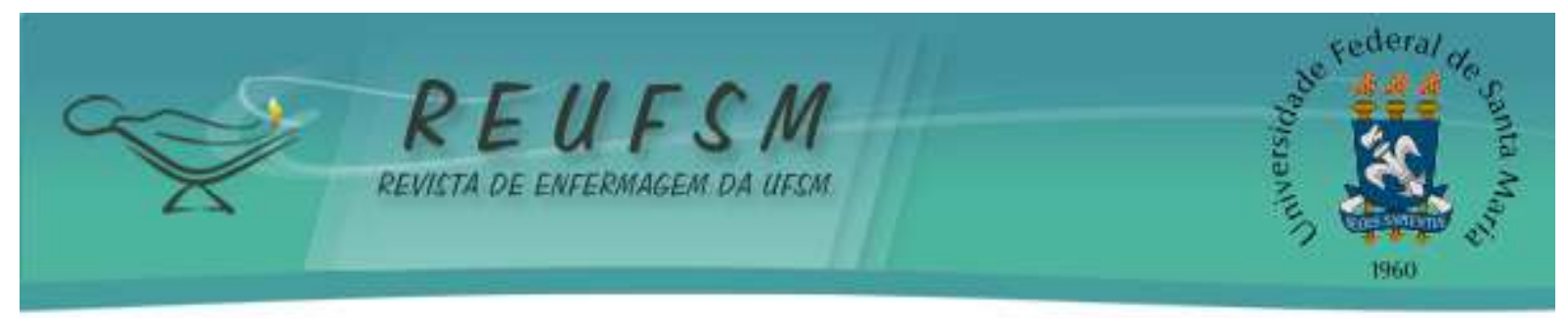

[...] Eu não sei tratar uma criança com deficiência e se vier vou pedir força a Deus e tratar, fazer o quê, mas é inseguro, eu me sinto insegura. (Íris)

[...] Eu tomei essa bebê um presente de Deus pra mim, e se Deus o livre ela viesse com microcefalia, eu ia aceitar do mesmo jeito. (Beladona)

Estudo sobre os sentimentos advindos da maternidade revelam que o fato da mulher estar gerando um filho, faz com que ela vivencie sentimentos de poder. ${ }^{18}$ Para outros autores, a espiritualidade pode ser vivenciada como um suporte emocional, um potencial racionalizador que leva um sentido positivo a vida das mulheres que enfrentam dificuldades durante a gestação, e oferece um suporte alternativo para criação de motivação para o enfrentamento. ${ }^{22}$

Esses achados remetem à importância de considerar os diversos fatores culturais na prática do cuidado de enfermagem; uma vez que a espiritualidade se constitui em um desses fortes elementos, e incorporá-la ao cuidado pode se tornar uma ferramenta relevante no processo de enfrentamento da gestante frente à possibilidade de dar a luz a uma criança com malformação.

\section{CONCLUSÃO}

Ainda que nenhuma das gestantes do estudo tenha apresentado infecção pelo Zika vírus, os relatos evidenciaram sentimentos de preocupação, medo e insegurança permeando todo o período gestacional, os quais estiveram relacionados ao medo de adquirir a infecção e, consequentemente, causar danos ao bebê. Apesar de a confirmação da normalidade do feto por meio do exame de ultrassom tranquilizar a gestante, ele também era considerado como fonte de ansiedade, pois as gestantes tinham possibilidades de contrair o Zika vírus a qualquer tempo do ciclo gestacional.

Sobre os recursos para enfrentar o cenário de surto do Zika vírus e suas potenciais consequências, as gestantes mencionaram estratégias significativas como a incorporação de novos cuidados à sua rotina pessoal; receber apoio de grupos de convivência; e recorrer à espiritualidade. Tais recursos proporcionaram um impacto positivo, refletido pelos relatos de sensação de tranquilidade.

Destaca-se que os métodos preventivos minimizam a insegurança e medo das gestantes, fazendo-se necessário, a implantação de ações estratégicas de educação para a saúde, direcionadas às famílias e sociedade em geral. Os enfermeiros, enquanto profissionais 


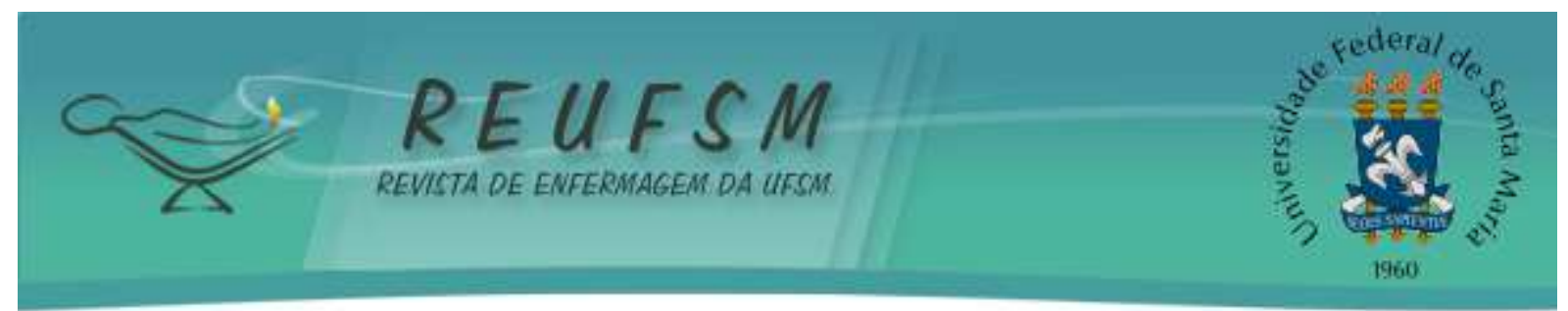

promotores da saúde, devem desenvolver e incentivar essas práticas, especialmente na Atenção Básica em Saúde, quando realizam os cuidados ao pré-natal de baixo risco.

Os enfermeiros, ao acompanharem o pré-natal de baixo risco na Estratégia Saúde da Família, podem beneficiar sua clientela ao transpor o cuidado direcionado ao bem-estar físico da mãe e do feto. Atender as demandas subjetivas diante do enfrentamento de situações circunstanciais envolve acolhida, empatia e escuta qualificada como estratégias de cuidado emocional.

Ressalta-se que esse estudo pode implicar no desenvolvimento de pesquisas que tragam novas práticas de cuidados e informações sobre a infecção pelo Zika vírus. Visto que as produções associadas a esta temática são incipientes, o estudo pode contribuir para a atenção à saúde direcionada às gestantes, pois ao identificar seus sentimentos e práticas de cuidados, é possível atentar para os aspectos subjetivos que permeiam uma gestação neste contexto de medo e tensão oferecendo-se, principalmente, apoio emocional e informacional.

Quanto à principal limitação do estudo, menciona-se o curto tempo para a conclusão da coleta de dados e não se permitir a generalização dos achados, uma vez que a definição dos critérios levou a pequena diversidade no perfil das participantes, envolvendo apenas a realidade local da Instituição de Ensino. Diante disso, sugere-se que esta temática seja investigada em outros cenários para se apreender possíveis percepções distintas de outras gestantes.

\section{REFERÊNCIAS}

1. Henriques CMP, Duarte E, Garcia LP. Desafios para o enfrentamento da epidemia de microcefalia. Epidemiol Serv Saúde [Internet]. 2016 mar [acesso em 2017 dez 18];25(1):0710. Disponível em: http://scielo.iec.gov.br/scielo.php?script=sci_arttext\&pid=S1679$49742016000100001 \& \operatorname{lng}=$ pt.

2. Brasil. Ministério da Saúde. Secretaria de Vigilância em Saúde. Boletim Epidemiológico. $2017 ;(48) 38$.

3. Luz KG, Santos GIV, Vieira RM. Febre pelo vírus Zika. Epidemiol Serv Saúde [Internet]. $2015 \mathrm{dez} \quad$ [acesso em $2017 \mathrm{dez} 18]$;24(4):785-8. Disponível em: http://www.scielo.br/scielo.php?script=sci_arttext\&pid=S2237$96222015000400785 \& \operatorname{lng}=$ en.

4. Linden VV, Rolim Filho EL, Lins OG, Linden AV, Aragão MF, Brainer-Lima AM, et al. Congenital zika syndrome with arthrogryposis: retrospective case series study. BMJ [Internet]. 2016 jul [acesso em 2016 jul 5];354:i3899. Disponivel em : https://www.ncbi.nlm.nih.gov/pubmed/27509902.

5. Brasil. Ministério da Saúde. Secretaria de Atenção à Saúde. Protocolo de atenção à saúde e resposta à ocorrência de microcefalia relacionada à infecção pelo vírus Zika. Brasília; 2016. 


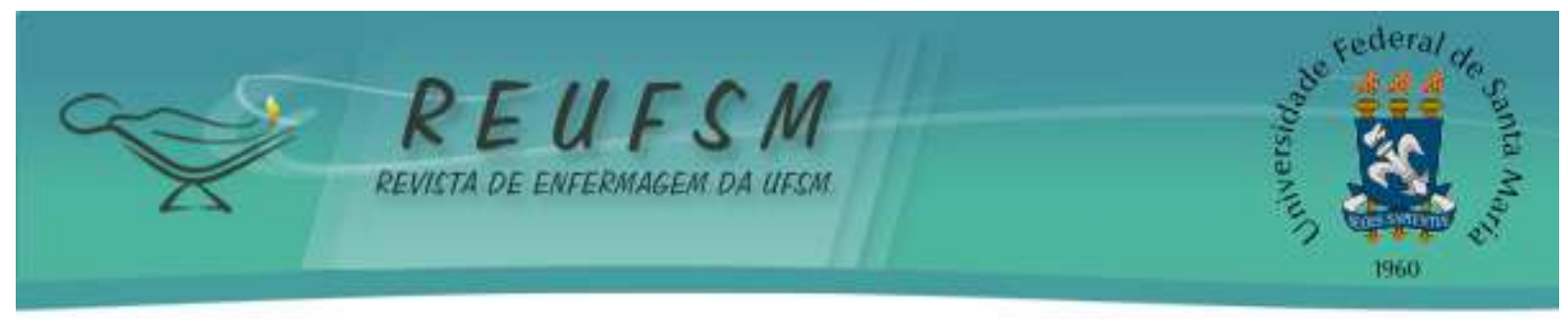

6. Brasil. Ministério da Saúde. Agência Nacional de Vigilância Sanitária. Diretoria Colegiada. Resolução RDC $n^{\circ}$ 19, de 10 de abril de 2013: Dispõe sobre os requisitos técnicos para a concessão de registro de produtos cosméticos repelentes de insetos e dá outras providências. Brasília; 2013.

7. Cruz RSBLC, Batista Filho M, Caminha MFC, Souza ES. Protocols on prenatal care for pregnant women with Zika infection and children with microcephaly: nutritional approach. Rev Bras Saúde Mater Infant [Internet]. 2016 nov [acesso em 2017 dez 18];16(Supl 1):S95S102. Disponivel em: http://www.scielo.br/scielo.php?script=sci_arttext\&pid=S1519$38292016000800008 \& \operatorname{lng}=$ en.

8. Vieira BD, Parizotto APAV. Alterações psicológicas decorrentes do período gravídico. Unoesc \& Ciência - ACBS [Internet]. 2013 jan/jun [acesso em 2017 dez 18];4(1):79-90. Disponível em: http://editora.unoesc.edu.br/index.php/acbs/article/view/2559.

9. Maynart WHC, Albuquerque MCS, Brêda MZ, Jorge JS. A escuta qualificada e o acolhimento na atenção psicossocial. Acta Paul Enferm [Internet]. 2014 ago [acesso em $2017 \mathrm{dez} 18] ; 27(4): 300-4$.

Disponível

em: http://www.scielo.br/scielo.php?script=sci_arttext\&pid=S0103-21002014000400003\&lng=pt.

10. Santos RP, Neves ET, Carnevale F. Metodologias qualitativas em pesquisa na saúde: referencial interpretativo de Patricia Benner. Rev Bras Enferm [Internet]. 2016 fev [acesso em 2017 dez 18];69(1):192-6.

Disponível

em: http://www.scielo.br/scielo.php?script=sci_arttext\&pid=S0034-71672016000100192\&lng=pt.

11. Fontanella BJB, Ronis MJ. Theoretical saturation in qualitative research: psychoanalytical contributions. Psicol Estud [Internet]. 2012 mar [acesso em 2017 dec 18];17(1):6371. Disponivel em: http://www.scielo.br/scielo.php?script=sci_arttext\&pid=S141373722012000100008 .

12. Minayo MCS. O desafio do conhecimento: pesquisa qualitativa em saúde. São Paulo (SP): Hucitec; 2014.

13. Brasil. Ministério da Saúde. Conselho Nacional de Saúde. Resolução no 466, de 12 de dezembro de 2012. Aprovar as seguintes diretrizes e normas regulamentadoras de pesquisas envolvendo seres humanos. Brasília; 2012.

14. Brunoni D, Blascovi-Assis SM, Osório AAC, Seabra AG, Amato CAH, Teixeira MCTV, et al. Microcefalia e outras manifestações relacionadas ao vírus Zika: impacto nas crianças, nas famílias e nas equipes de saúde. Ciênc Saúde Colet [Internet]. 2016 out [acesso em 2017 dez 18];21(10):3297-3302. Disponível http://www.scielo.br/scielo.php?script=sci_arttext\&pid=S1413$81232016001003297 \& \operatorname{lng}=$ pt.

15. Barreto CN, Ressel LB, Santos CC, Wilhelm LA, Silva SC, Alves CN. Atenção pré-natal na voz das gestantes. Rev Enferm UFPE [Internet]. 2013 jun [acesso em 2017 dez 18];7(6):4354-63. Disponível

em: https://periodicos.ufpe.br/revistas/revistaenfermagem/article/view/11674/13851.

16. Salge AKM, Castral TC, Sousa MC, Souza RRG, Minamisava R, Souza SMB. Infecção pelo vírus Zika na gestação e microcefalia em recém-nascidos: revisão integrativa de 


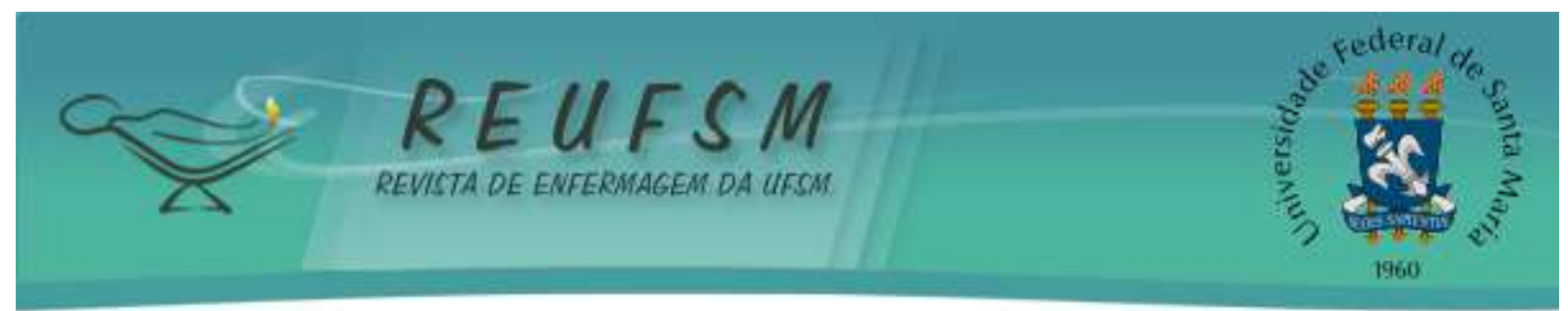

literatura. Rev Eletr Enf [Internet]. 2016 mar [acesso em 2017 dez 18];18:e1137. Disponível em: https://revistas.ufg.br/fen/article/view/39888.

17. Guerreiro EM, Rodrigues DP, Silveira MAMD, Lucena NBFD. O cuidado pré-natal na atenção básica de saúde sob o olhar de gestantes e enfermeiros. Rev Min Enferm [Internet]. 2012 jul/set [acesso em 2017 dez 18];16(3):315-23. Disponível em: http://www.dx.doi.org/S1415-27622012000300002.

18. Leite MG, Rodrigues DP, Sousa AAS, Melo LPT, Fialho AVM. Sentimentos advindos da maternidade: revelações de um grupo de gestantes. Psicol Estud [Internet]. 2014 [acesso em 2017 dez 18];19(1):115-24. Disponível em: http://www.scielo.br/scielo.php?pid=S1413$73722014000100013 \&$ script=sci_abstract\&tlng=pt.

19. Brasil. Ministério da Saúde. O mosquito da dengue pode matar: e é ainda mais perigoso para gestantes [Internet]. Brasília; 2015 dez 08 [acesso em 2017 dez 18]. Disponível em http://portalarquivos2.saude.gov.br/images/campanhas/dengue2015/Broadside_Microcefalia_ 20x28_V2.pdf.

20. Zara ALSA, Santos SM, Oliveira ESF, Carvalho RG, Coelho GE. Estratégias de controle do Aedes aegypti: uma revisão. Epidemiol Serv Saúde [Internet]. 2016 jun [acesso em 2017 dez 18];25(2):391-404. Disponível em: http://www.scielo.br/scielo.php?script=sci_arttext\&pid=S2237-

$96222016000200391 \& \operatorname{lng}=\mathrm{em}$.

21. Simas FB, Souza LV, Comin FS. Significados da gravidez e da maternidade: discursos de primíparas e multíparas. Rev Psicol Teor Prat [Internet]. 2013 abr [acesso em 2017 dez 18];15(1):19-34. Disponível em: http://pepsic.bvsalud.org/scielo.php?script=sci_arttext\&pid=S151636872013000100002\&lng=pt\&nrm=iso.

22. Barros VC, Santos JFC, Lima LA, Fonseca DL, Lovisi GM. Depressão e apoio social em gestantes de fetos com malformações atendidas em um hospital materno-infantil público de referência no Rio de Janeiro. Cad Saúde Colet [Internet]. 2013 [acesso em 2017 dez 18]; 21(4):391-402. Disponível em: http://www.scielo.br/scielo.php?script=sci_arttext\&pid=S1414462X2013000400006\&lng=pt.

Data de submissão: 19/12/2017

Data de aceite: 18/06/2018

Autor correspondente: Francisca Weslla Oliveira da Silva

E-mail: weslla_enfa@hotmail.com

Endereço: Rua Epifânio Leite , 135 - Jacarecanga. Fortaleza, CE, Brasil.

CEP: 60010-582 